\title{
Nivolumab Induced Toxicity Presenting As Pneumonitis- A Case Report
}

\author{
Vulisha $A K^{1}$, Talwar $A^{1,2^{\star}}$, Verma $S^{1,2,3}$, Gupta $A^{4}$, Lam $L^{5}$, Bhushan $S^{1,6}$ and Singh $R^{1,6}$ \\ ${ }^{1}$ Department of Pulmonary, Critical Care and Sleep Medicine, Northwell Health, New York, USA \\ ${ }^{2}$ Department of Heart and Lung Research, The Feinstein Institute for Medical Research, Northwell Health System, Manhasset, New York, USA \\ ${ }^{3}$ Touro College of Osteopathic Medicine, New York, USA \\ ${ }^{4}$ Advantage Care Physicians, Plainview Hospital, New York, USA \\ ${ }^{5}$ Department of Family Medicine, Group Glen Cove Hospital, Glen Cove, New York, USA \\ ${ }^{6}$ College of Osteopathic Medicine, New York Institute of Technology (NYIT), New York, USA
}

\begin{abstract}
Nivolumab is a recently approved medication that shows significant clinical activity for various types of malignancies such melanoma, renal cell carcinoma and non-small cell carcinoma. Pneumonitis is a rare, but, possibly fatal manifestation that still remains ambiguous. This article presents a case of nivolumab induced pneumonitis in a patient with melanoma and discusses management plans.
\end{abstract}

Keywords: Nivolumab; Drug induced pneumonitis; Steroids; Melanoma; Checkpoint inhibitor; Crytogenic organizing pneumonia

\section{Case Report}

A 64 year old Caucasian woman was diagnosed with melanoma (nodular melanoma) of the left arm two years ago. The initial skin lesion measured $3.7 \mathrm{~mm}$ in thickness and a size of $1.2 \mathrm{~cm}$. A sentinel lymph node biopsy was negative for any malignant process. She was treated for melanoma with chemotherapy and had a significant response.

The patient has a past medical history of Type II Diabetes Mellitus, hypothyroidism, and hypertension; She has no past history of smoking. Her current medications include atorvastatin, glimepiride, hydrochlorothiazide, canagliflozin, levothyroxine, metformin, oxycodone, quinapril, liraglutide.

Eight months ago, a routine ultrasound of the right upper quadrant revealed multiple hepatic lesions. A subsequent liver biopsy demonstrated metastatic melanoma of the liver. It was also found that the patient has a BRAF V600E mutation. An MRI of the spine demonstrated a metastatic lesion within the T10 with anterior and left lateral epidural extension resulting in moderate canal stenosis. The patient underwent stereotactic body radiotherapy, and immunotherapy. The patient was started on nivolumab. After second cycle of nivolumab treatment, the patient complained of increasing shortness of breath.

On her physical exam, she was alert, awake and oriented. Her pulse was 80 per minute, blood pressure $120 / 80 \mathrm{mmHg}$, respiratory rate 18 per minute, and oxygen saturation was $96 \%$. Respiratory examinations revealed decreased air entry in both the lung bases. A chest X-ray revealed bilaterally increased lung marking and infiltrates in both lung bases (Figure 1). A PET/CT scan demonstrated new mildly hypermetabolic diffuse bilateral ground glass pulmonary opacities, in view of rapidly deterioration of her pulmonary symptoms after starting nivolumab.

Pulmonary Function Tests (PFTs) suggested restrictive ventilatory defect with moderate decrease in DLCO, thereby suggesting underlying gas exchange abnormality (Table 1). A diagnosis of nivolumab lung toxicity was entertained. Treatment with nivolumab was halted and the patient was started on Prednisone, $20 \mathrm{mg}$ per day. At her subsequent visit after 6 weeks, she reported significant improvement in her dyspnea. Repeat set of pulmonary function tests showed improvement in DLCO as well (Table 1). A repeat chest X-Ray also showed an improvement in the previously reported infiltrates (Figure 2).

Nivolumab, a form of target therapy, is an antibody that blocks the

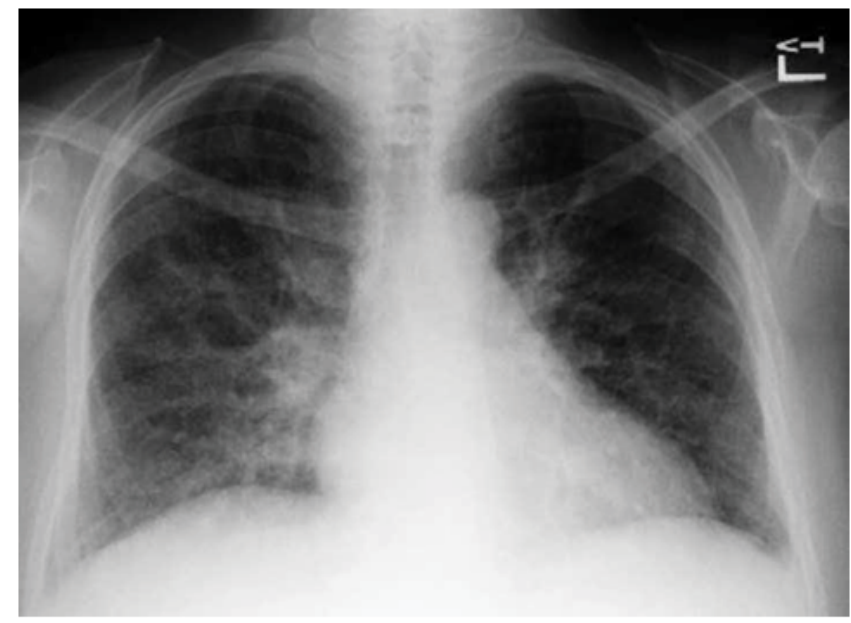

Figure 1: Chest X-ray at initial presentation shows bilaterally Increased lung marking and infiltrates in both lung bases.

\begin{tabular}{|c|c|c|c|c|}
\hline Date & FVC (Liters) & FEV1 (Liters) & $\begin{array}{c}\text { FEV1/ } \\
\text { FVC }\end{array}$ & $\begin{array}{c}\text { DLCO (mL/mm/ } \\
\mathbf{H g} / \mathbf{m i n})\end{array}$ \\
\hline Initial Visit & $\begin{array}{c}1.86(66 \% \\
\text { Predicted) }\end{array}$ & $\begin{array}{c}1.54(72 \% \\
\text { predicted) }\end{array}$ & 0.83 & $\begin{array}{c}11.6(59 \% \text { of } \\
\text { Predicted) }\end{array}$ \\
\hline $\begin{array}{c}\text { Subsequent } \\
\text { Visit }\end{array}$ & $\begin{array}{c}2.29(81 \% \\
\text { Predicted) }\end{array}$ & $\begin{array}{c}2.13(100 \% \\
\text { Predicted) }\end{array}$ & 0.93 & $\begin{array}{c}15.8(80 \% \text { of } \\
\text { Predicted) }\end{array}$ \\
\hline
\end{tabular}

Table 1: Initial pulmonary function tests vs. follow-up.

*Corresponding author: Arunabh Talwar, Department of Pulmonary, Critical Care and Sleep Medicine, Northwell Health, New York, USA, Tel: 516-465-5400; Fax: 516-465-5455; E-mail: arunabh@northwell.edu

Received April 06, 2018; Accepted April 16, 2018; Published April 21, 2018

Citation: Vulisha AK, Talwar A, Verma S, Gupta A, Lam L, et al. (2018) Nivolumab Induced Toxicity Presenting As Pneumonitis- A Case Report. J Pulm Respir Med 8: 455. doi: 10.4172/2161-105X.1000455

Copyright: (c) 2018 Vulisha AK, et al. This is an open-access article distributed under the terms of the Creative Commons Attribution License, which permits unrestricted use, distribution, and reproduction in any medium, provided the original author and source are credited. 


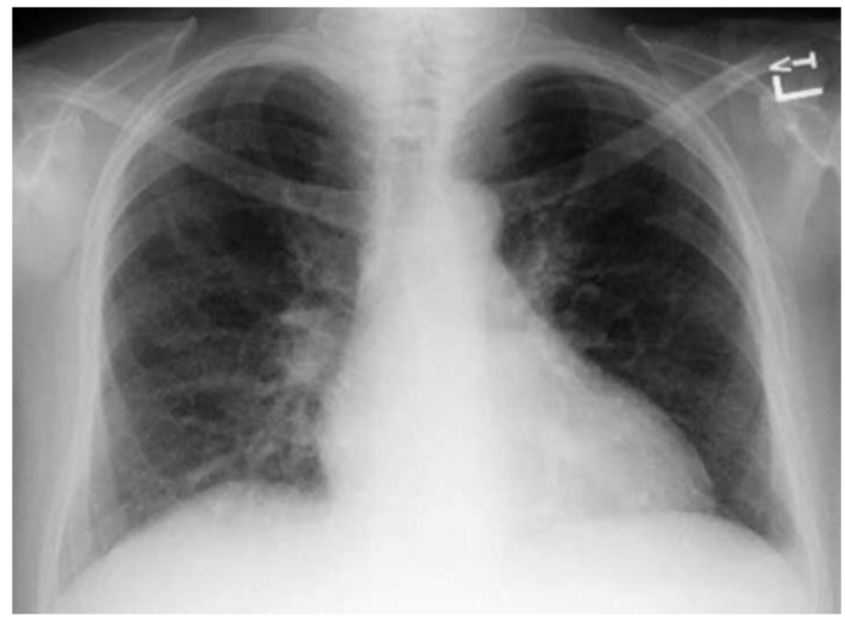

Figure 2: Chest X-Ray show improvement is pulmonary infiltrates after 6 weeks of treatment with steroids.

\begin{tabular}{|c|l|l|}
\hline Grade & Symptom & Management \\
\hline 1 & Asymptomatic & $\begin{array}{l}\text { Continue monitoring symptoms, follow up } \\
\text { with repeat CT Scans }\end{array}$ \\
\hline 2 & $\begin{array}{l}\text { Mild to moderate } \\
\text { Symptomatic; limiting } \\
\text { IADLs }\end{array}$ & $\begin{array}{l}\text { Stop immunotherapy, Start } \\
\text { Methylprednisone, Repeat CT on physician } \\
\text { discretion }\end{array}$ \\
\hline $3-4$ & $\begin{array}{l}\text { Severe symptoms; } \\
\text { limiting self- care } \\
\text { ADLs, Life threatening } \\
\text { respiratory failure }\end{array}$ & $\begin{array}{l}\text { Admission to ICU, Start Methylprednisolone } \\
\text { and taper over 6 weeks, Start other } \\
\text { immunotherapy (if no change within 48 } \\
\text { hours) }\end{array}$ \\
\hline 5 & Death & - \\
\hline
\end{tabular}

Table 2: Pneumonitis severity assessment based on CTCAE.

PD-1 human programmed death receptor which many cancer cells use to hide from the body's immune system. A side effect of nivolumab is drug induced pneumonitis. We believe the patient shortness of breath, decreased DLCO and initial pulmonary infiltrate were due to drug induced pneumonitis (DIP) caused by nivolumab.

\section{Discussion}

Nivolumab is a human IgG4 programmed death 1 (PD 1) monoclonal antibody that works as an immune check point inhibitor (ICI) [1]. It inhibits the binding of PD 1 to both programmed deathligand 1 (PD L1) and programmed death- ligand (PD L2), that are found on tumor cells, and help regulate balance of $\mathrm{T}$ cell activation $[1,2]$. In patients with cancer, when these ligands bind to the PD-1 receptor results in declining $\mathrm{T}$ - cell activity and in turn allow cancer cells to elude the immune system.

Recent research shows a great promise in this class of medication, as a result they have revolutionized cancer treatments, to a point that they are rapidly becoming standard of care, in various malignancies, such Melanoma [3], Renal cell carcinoma [4], Non-small cell carcinoma (NSCLC) [5].

Yet, the benefits of this novel approach have revealed some unwanted side effects, such as drug related pneumonitis (DIP). Approximately, 2-4\% patients treated with nivolumab have developed drug related pneumonitis [6,7]. Patients generally present with cough, dyspnea, hypoxia that can make diagnosis of drug induced pneumonitis challenging because these signs/symptoms are also suggestive of pneumonia, pulmonary edema or alveolar hemorrhage as well [8]. For this reason, DIP is a diagnosis of exclusion. Risk factors associated with DIP are unknown [6]. Study by Naidoo et al. observed that DIP was common in $56 \%$ ( 24 of 43 ) who were both current and former smokers while, $44 \%$ of patients were never smokers [9]. The development of pneumonitis can be variable from the time of initiation of therapy [9]. Study by Naidoo et al., indicated that the median onset of pneumonitis was 2.8 months with a wide range of (9 days to 19.2 months) in 43/915 patients who developed pneumonitis [9]. Similarly, another study by Nishino et al., revealed a median time of 2.6 months (range $0.5-11.5$ ) [10]. The presence of pneumonitis can lead to a decrease in DLCO [11]. Diffusion capacity of carbon monoxide gives the clinicians an idea about the stability of alveolar capillary membrane in the lungs. In the presence of acute pneumonitis, as the gas exchange is impeded the DLCO also decreases. Once the patient recovers, DLCO increases accordingly [11].

As in our case, a chest $\mathrm{x}$-ray can show increased interstitial markings, which is reflective of acute pneumonitis. One can also obtain high resolution CT scan to better evaluate the alveolar/ interstitial structure. DIP may present on CT scan, most commonly, as cryptogenic organizing pneumonia (COP). Aside from COP, it can present as nonspecific interstitial pneumonitis (NSIP), hypersensitivity pneumonitis (HP), or usual interstitial pneumonitis (UIP)/pulmonary fibrosis (PF) $[9,10]$. In some cases, pneumonitis can appear on CT scan even before any clinical symptoms are apparent, however, some patients can still remain asymptomatic $[9,12]$.

From a clinical perceptive, there is some variability of in severity of DIP. As per Common Terminology Criteria for Adverse Events (CTCAE), asymptomatic patients with some radiographic changes are classified as grade 1 , while patients with mild to moderate symptoms with varying radiographic infiltrates are considered grade 2 [13] Furthermore, patients with severe symptoms or symptoms that can lead to life threatening respiratory complications are classified as grade 3 and 4, respectively (Table 2) [13].

Treatment options can range from outpatient management with steroids for grade 2 pneumonitis, to admission in intensive care unit for patients with grade 3-4 severity [13-15]. In more severe cases, anti TNFa, such as infliximab, or immunosuppressive therapy with mycophenolate mofetil can be administered [14]. Patients with grade 3-4 severity, a bronchoscopic evaluation is suggested to rule out infectious or other etiology [13]. Roughly, one third of patients, after treatment with steroids are able to restart PD-1 inhibitor therapy [10]. However, it is not recommended to use any check point inhibitor mediations in patients with moderate to severity pneumonitis [13].

\section{Conclusion}

With the availability of newer such agents, clinicians may face similar cases much more frequently with the use of Anti-PD1 antibodies. Thus, clinicians must be aware of various presentations of drug induced pneumonitis so it can be diagnosed timely and treated appropriately.

\section{References}

1. Brahmer JR, Drake CG, Wollner I, Powderly JD, Picus J et al (2010) Phase I study of single-agent anti-programmed death-1 (mdx-1106) in refractory solid tumors: Safety, clinical activity, pharmacodynamics, and immunologic correlates. J Clin Oncol 28: 3167-3175.

2. Hamanishi J, Mandai M, Ikeda T, Minami M, Kawaguchi A, et al. (2015) Safety and antitumor activity of anti-pd-1 antibody, nivolumab, in patients with platinum-resistant ovarian cancer. J Clin Oncol 33: 4015-4022.

3. Weber JS, D'Angelo SP, Minor D, Hodi FS, Gutzmer R, et al. (2015) Nivolumab versus chemotherapy in patients with advanced melanoma who progressed 
after anti-ctla-4 treatment (checkmate 037): A randomised, controlled, openlabel, phase 3 trial. Lancet Oncol 16: 375-384

4. Motzer RJ, Escudier B, McDermott DF, George S, Hammers HJ, et al. (2015) Nivolumab versus everolimus in advanced renal-cell carcinoma. New Eng J Med 373: 1803-1813.

5. Herbst RS, Baas P, Kim DW, Felip E, Perez-Gracia JL, et al. (2016) Pembrolizumab versus docetaxel for previously treated, pd-11-positive, advanced non-small-cell lung cancer (keynote-010): A randomised controlled trial. Lancet 387: 1540-1550.

6. Nishino M, Giobbie-Hurder A, Hatabu H, Ramaiya NH, Hodi FS (2016) Incidence of programmed cell death 1 inhibitor-related pneumonitis in patients with advanced cancer: A systematic review and meta-analysis. JAMA Onco 2: $1607-1616$.

7. Topalian SL, Hodi FS, Brahmer JR, Gettinger SN, Smith DC, et al. (2012) Safety, activity, and immune correlates of anti-pd-1 antibody in cancer. New Eng J Med 366: 2443-2454

8. Sano T, Uhara H, Mikoshiba Y, Kobayashi A, Uchiyama R, et al. (2016) Nivolumab-induced organizing pneumonia in a melanoma patient. Jpn J Clin Oncol 46: 270-272.

9. Naidoo J, Wang X, Woo KM, lyriboz T, Halpenny D, et al. (2017) Pneumonitis in patients treated with anti-programmed death-1/programmed death ligand 1 therapy. J Clin Oncol 35: 709-717.

10. Nishino M, Ramaiya NH, Awad MM, Sholl LM, Maattala JA, et al. (2016) $\mathrm{Pd}-1$ inhibitor-related pneumonitis in advanced cancer patients: Radiographic patterns and clinical course. Clin Cancer Res 22: 6051-6060.

11. Enright P (2016) Office-based DLCO tests help pulmonologists to make important clinical decisions. Respiratory investigation 54: 305-311.

12. Tirumani SH, Ramaiya NH, Keraliya A, Bailey ND, Ott PA, et al. (2015 Radiographic profiling of immune-related adverse events in advanced melanoma patients treated with ipilimumab. Cancer Immunol Res 3: 11851192.

13. Chuzi S, Tavora F, Cruz M, Costa R, Chae YK, et al. (2017) Clinical features diagnostic challenges, and management strategies in checkpoint inhibitorrelated pneumonitis. Cancer Manag Res 9: 207-213.

14. Friedman CF, Proverbs-Singh TA, Postow MA (2016) Treatment of the immune-related adverse effects of immune checkpoint inhibitors: A review. JAMA Oncol 2: 1346-1353.

15. Naidoo J, Page DB, Li BT, Connell LC, Schindler K, et al. (2015) Toxicities of the anti-pd-1 and anti-pd-I1 immune checkpoint antibodies. Annals of oncology: official journal of the European Society for Medical Oncology 26: 2375-2391. 